\title{
Prognostic Factors in Elderly Patients With Supratentorial Malignant Gliomas
}

\author{
Masanori KURIMOTO, Shoichi NAGAI, Hironaga KAMIYAMA, Yoshifumi TSUBOI, \\ Kunikazu KUROSAKI, Nakamasa HAYASHI, Hideki ORIGASA*, and Shunro ENDO
}

\author{
Department of Neurosurgery, University of Toyama, Toyama; *Division of Biostatistics and \\ Clinical Epidemiology, University of Toyama Graduate School, Toyama
}

\begin{abstract}
The prognostic factors were retrospectively analyzed in 30 patients aged 70 years or over with supratentorial malignant gliomas treated by surgery in our hospital. The histological diagnosis was confirmed as grade 3 in 13 patients and grade 4 in 17. Seventeen patients received adjuvant radiation therapy. Only 10 patients underwent chemotherapy. Survival time was analyzed with the Kaplan-Meier method. Prognostic factors were obtained from the Cox proportional hazards model. Univariate analysis showed preoperative Karnofsky performance status (KPS) score of 70 or greater and radiation therapy were significantly associated with longer survival. However, multivariate analysis revealed that preoperative KPS score of 70 or greater was the only independent prognostic factor and radiation therapy lost its significance due to selection bias. Neurological deterioration and medical complications occurred in six and seven patients, respectively. Performance status rather than histological grade is the key prognostic factor in elderly patients with supratentorial malignant gliomas. Patients with good preoperative KPS score should be aggressively treated with extensive resection and radiotherapy.
\end{abstract}

Key words: malignant astrocytoma, elderly patient, radiation therapy, survival time, performance status

\section{Introduction}

Evidence is growing that the incidence of malignant gliomas has increased substantially in the elderly population, especially in industrialized countries, over the past three decades. ${ }^{9,11,12,14,18,36,44)}$ Numbers of primary brain tumors have nearly doubled in the 65to 74-year-old population and have more than doubled in the 75- to 84-year-old population. ${ }^{11)}$ These increasing trends may result from a combination of a true increase in the incidence, a gain in life expectancy, and exposure to increasing environmental carcinogens, ${ }^{18)}$ as well as improved diagnostic procedures and better access of the elderly to health care. ${ }^{36)}$

Aggressive treatment has been questioned for elderly patients. ${ }^{21,32,35)}$ In addition, elderly patients have frequently been undertreated or untreated. ${ }^{5,26)}$ Surprisingly, a retrospective cohort study in Minnesota found that the proportion of elderly patients receiving no treatment increased from $4 \%$ between

Received February 14, 2007; Accepted September 6, 2007
1980 and 1989 to $18 \%$ between 1990 and $1995 .^{26)}$ However, elderly patients with brain tumors should be treated based on sound scientific data and not ad hoc decisions. ${ }^{4}$ Several prognostic factors have been identified in patients with malignant glioma, including age, performance status, histological grade, and extent of resection. ${ }^{10,13,20-25,30-33,38)}$ Age is considered a strong negative factor on survival. ${ }^{10,21-25,32,35,38)}$ However, age should not be a reason for exclusion from aggressive treatment, ${ }^{5,27,39,45)}$ because the few investigations of the treatment of malignant gliomas in the elderly ${ }^{4,10)}$ have not defined the prognostic factors in this subgroup.

The present retrospective study tried to identify the independent variables that are significant predictors of survival time in elderly patients with malignant astrocytomas.

\section{Methods}

\section{Patient population}

The clinical records were retrospectively reviewed of 30 elderly patients, 17 men and 13 women aged 70 to 81 years (median 73.0 years) at first admis- 
sion, who were surgically treated for histologically confirmed supratentorial malignant astrocytomas at our University Hospital between April 1980 and December 2005. The most frequent symptoms were dementia in 14 patients, hemiparesis in 13, and visual disturbance in eight. The histological diagnosis was glioblastoma multiforme (grade 4) in 17 patients, and anaplastic astrocytoma or anaplastic oligodendroglioma (grade 3 ) in 13. At the end point of the study on August 31, 2006, two patients were alive and 28 had died. The clinical characteristics are summarized in Table 1.

\section{Treatment characteristics}

All patients were treated using standard microneurosurgical techniques. Our standard surgical policy was debulking as far as possible and preservation of neurological functions. Needle biopsy was not performed in this series. Gross total resection, defined as the complete absence of residual enhanced tumor on early postoperative magnetic resonance imaging or computed tomography, was

Table 1 Clinical characteristics of the patients

\begin{tabular}{|c|c|c|c|c|c|c|c|c|c|c|c|c|}
\hline \multirow{2}{*}{$\begin{array}{l}\text { Case } \\
\text { No. }\end{array}$} & \multirow{2}{*}{$\begin{array}{l}\text { Age } \\
\text { (yrs) }\end{array}$} & \multirow{2}{*}{ Sex } & \multirow{2}{*}{$\begin{array}{l}\text { Survival } \\
\text { (mos) }\end{array}$} & \multirow{2}{*}{$\begin{array}{l}\text { Tumor } \\
\text { grade }\end{array}$} & \multirow{2}{*}{ Resection } & \multicolumn{2}{|c|}{ KPS (\%) } & \multirow{2}{*}{$\begin{array}{l}\text { Surgical } \\
\text { result }\end{array}$} & \multirow{2}{*}{ Radiation } & \multirow{2}{*}{$\begin{array}{l}\text { Chemo- } \\
\text { therapy }\end{array}$} & \multicolumn{2}{|c|}{ Complication } \\
\hline & & & & & & Preop. & Postop. & & & & Surgical & Medical \\
\hline 1 & 76 & $\mathrm{M}$ & 12 & 4 & partial & 80 & 80 & $\mathrm{NC}$ & no & no & & \\
\hline 2 & 73 & $\mathrm{M}$ & 2 & 4 & partial & 40 & 30 & worse & no & no & aphasia & septicemia \\
\hline 3 & 76 & $\mathrm{~F}$ & 18 & 4 & $\begin{array}{l}\text { gross } \\
\text { total }\end{array}$ & 90 & 90 & $\mathrm{NC}$ & yes & no & & \\
\hline 4 & 77 & $\mathrm{~F}$ & 8 & 4 & partial & 70 & 50 & worse & no & no & $\begin{array}{c}\text { consciousness } \\
\text { disturbance }\end{array}$ & \\
\hline 5 & 70 & $\mathrm{M}$ & 12 & 4 & partial & 70 & 80 & improve & yes & yes & & \\
\hline 6 & 74 & $\mathrm{~F}$ & 4 & 4 & $\begin{array}{l}\text { gross } \\
\text { total }\end{array}$ & 60 & 70 & improve & yes & yes & & \\
\hline 7 & 70 & $\mathrm{~F}$ & 14 & 4 & partial & 60 & 90 & improve & no & no & & \\
\hline 8 & 71 & $\mathrm{M}$ & 18 & 4 & $\begin{array}{l}\text { gross } \\
\text { total }\end{array}$ & 80 & 100 & improve & yes & yes & & \\
\hline 9 & 71 & $\mathrm{M}$ & 24 & 4 & $\begin{array}{l}\text { gross } \\
\text { total }\end{array}$ & 70 & 90 & improve & yes & yes & & \\
\hline 10 & 72 & $\mathrm{~F}$ & 5 & 4 & partial & 60 & 100 & improve & no & no & & \\
\hline 11 & 70 & $\mathrm{M}$ & 5 & 4 & partial & 60 & 50 & worse & yes & no & hemiparesis & $\begin{array}{l}\text { pulmonary } \\
\text { embolism }\end{array}$ \\
\hline 12 & 81 & $\mathrm{~F}$ & 8 & 4 & $\begin{array}{l}\text { gross } \\
\text { total }\end{array}$ & 70 & 80 & improve & no & no & hematoma & \\
\hline 13 & 71 & $\mathrm{M}$ & 4 & 4 & partial & 50 & 50 & $\mathrm{NC}$ & no & no & & pneumonia \\
\hline 14 & 72 & $\mathrm{~F}$ & 3 & 4 & partial & 50 & 50 & NC & no & no & & ketoacidosis \\
\hline 15 & 70 & $\mathrm{M}$ & 12 & 4 & partial & 60 & 60 & $\mathrm{NC}$ & yes & no & & \\
\hline 16 & 76 & $\mathrm{M}$ & 4 & 4 & partial & 50 & 50 & $\mathrm{NC}$ & yes & no & & \\
\hline 17 & 78 & $\mathrm{~F}$ & 10 & 4 & $\begin{array}{l}\text { gross } \\
\text { total }\end{array}$ & 70 & 70 & $\mathrm{NC}$ & no & no & & \\
\hline 18 & 76 & $\mathrm{M}$ & 9 & 3 & partial & 80 & 60 & worse & no & no & hemiparesis & \\
\hline 19 & 71 & $\mathrm{~F}$ & 17 & 3 & partial & 70 & 70 & $\mathrm{NC}$ & yes & yes & & \\
\hline 20 & 76 & $\mathrm{~F}$ & 6 & 3 & $\begin{array}{l}\text { gross } \\
\text { total }\end{array}$ & 50 & 80 & improve & no & no & & \\
\hline 21 & 70 & $\mathrm{~F}$ & 22 & 3 & $\begin{array}{l}\text { gross } \\
\text { total }\end{array}$ & 80 & 80 & $\mathrm{NC}$ & yes & yes & & \\
\hline 22 & 73 & $\mathrm{M}$ & 7 & 3 & $\begin{array}{l}\text { gross } \\
\text { total }\end{array}$ & 80 & 60 & $\mathrm{NC}$ & yes & no & & pneumonia \\
\hline 23 & 73 & $\mathrm{~F}$ & 11 & 3 & partial & 60 & 50 & worse & no & no & hemiparesis & pneumonia \\
\hline 24 & 72 & $\mathrm{M}$ & 36 & 3 & $\begin{array}{l}\text { gross } \\
\text { total }\end{array}$ & 80 & 80 & $\mathrm{NC}$ & yes & yes & & \\
\hline 25 & 70 & $\mathrm{M}$ & 72 & 3 & $\begin{array}{l}\text { gross } \\
\text { total }\end{array}$ & 80 & 50 & worse & yes & no & hemiparesis & \\
\hline 26 & 71 & $\mathrm{M}$ & 13 & 3 & $\begin{array}{l}\text { gross } \\
\text { total }\end{array}$ & 60 & 80 & improve & no & no & & pneumonia \\
\hline 27 & 71 & $\mathrm{M}$ & 8 & 3 & partial & 60 & 60 & $\mathrm{NC}$ & yes & no & & \\
\hline 28 & 74 & $\mathrm{M}$ & 5 & 3 & $\begin{array}{l}\text { gross } \\
\text { total }\end{array}$ & 50 & 100 & improve & yes & yes & & \\
\hline 29 & 70 & $\mathrm{~F}$ & 12 & 3 & $\begin{array}{l}\text { gross } \\
\text { total }\end{array}$ & 80 & 80 & $\mathrm{NC}$ & yes & yes & & \\
\hline 30 & 70 & $\mathrm{M}$ & 20 & 3 & partial & 80 & 80 & NC & yes & yes & & \\
\hline
\end{tabular}

KPS: Karnofsky performance status, NC: no change. 
achieved in 14 patients, and partial resection in 16 . Reoperation for recurrent tumor was performed in six patients. Postoperative adjuvant radiotherapy was routinely initiated 2 or 3 weeks after tumor removal, except for patients aged over 80 years or patients in poor neurological or general condition. Linac external beam conventional radiation therapy was administered to the residual tumor or tumor cavity with a margin of $2 \mathrm{~cm}$ using 2 Gy daily, 5 days a week, up to a total of $40 \mathrm{~Gy}$. The dosage was boosted to a total of 54 to $60 \mathrm{~Gy}$ to the whole brain or to the extended local tumor. Radiation therapy was completed in 17 patients, consisting of local plus whole brain irradiation in six and local plus extended local irradiation in 11. Stereotactic booster irradiation was carried out in six patients using either gamma knife (4) or NOVARIS methods (2). Chemotherapy with nimustine hydrochloride (ACNU) was given to 10 patients with good postoperative Karnofsky performance status (KPS) score $(\geq 70)$.

\section{Statistical analysis}

Survival time was retrospectively analyzed using the Kaplan and Meier method, and survival curves for the various subgroups were compared using the log-rank test. The Cox proportional hazards model was used to identify the multivariate independent predictors of survival. The five clinical parameters examined were tumor grade (grade 3 vs. grade 4), ex- tent of tumor resection (gross total resection vs. partial resection), preoperative and postoperative KPS scores (KPS $\geq 70$ vs. KPS $<70$ ), and radiation therapy (with vs. without).

\section{Results}

No operative death occurred in our series. One patient required immediate reoperation for postoperative hematoma evacuation, but fully recovered. Postoperative improvement of symptoms was observed in 10 patients, but no improvement was found in 14. Six patients suffered postoperative neurological deterioration; deteriorated hemiparesis in four patients, and aphasia and consciousness disturbance in one patient each. Three of these cases of postoperative neurological deterioration were transient, but another three persisted. Medical complications occurred in seven patients within 30 postoperative days; pneumonia in four patients, pulmonary embolism in one, diabetic ketoacidosis in one, and septicemia in one. Mean preoperative and postoperative KPS scores were 66.7 and 70.7, respectively.

Patients had survival times of 2 to 72 months. The median survival was 10.5 months. Survival curves of patients with the independent prognostic factors were fitted to stratified proportional hazard models using the Kaplan and Meier method (Fig. 1). Univariate analysis showed preoperative KPS score $\geq 70$ and radiotherapy were significant $(p<0.05)$
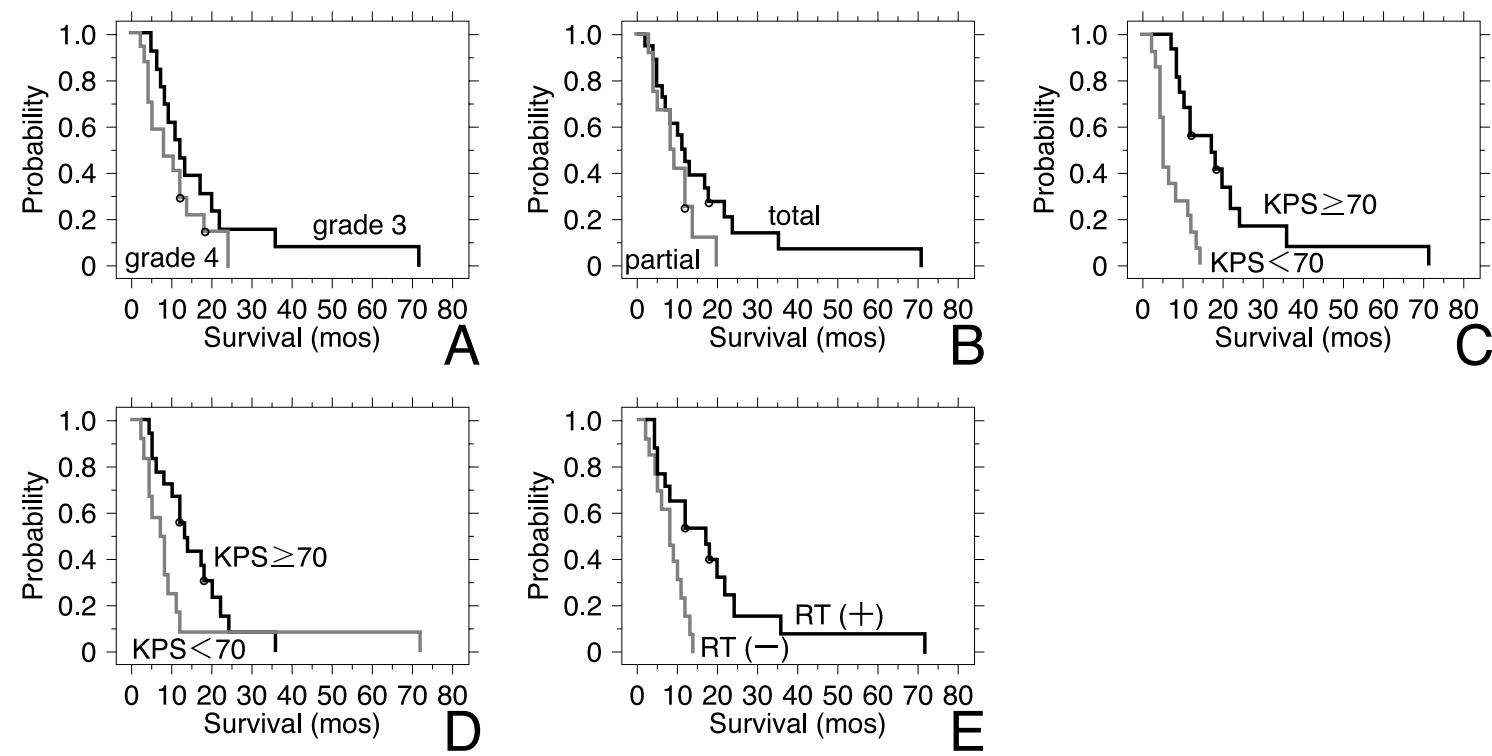

Fig. 1 Kaplan-Meier estimated survival curves of the 30 elderly patients with malignant astrocytomas stratified by the tumor grade $(A, p=0.1383)$, extent of resection $(B, p=0.1705)$, preoperative Karnofsky performance status (KPS) score (C, $p=0.0001)$, postoperative KPS score $(D, p=0.1796)$, and radiation therapy $(R T)(E, p=0.0043)$. 
Table 2 Multivariate analyses of survival predictors

\begin{tabular}{lcc}
\hline & p Value & $\begin{array}{c}\text { Hazard radio } \\
\text { (95\% confidence interval) }\end{array}$ \\
\hline Grade 3 & 0.2209 & $0.549(0.210-1.435)$ \\
Total resection & 0.7819 & $1.155(0.413-3.203)$ \\
Preop. KPS $\geq 70^{*}$ & 0.0177 & $0.297(0.109-0.810)$ \\
Postop. KPS $\geq 70$ & 0.1550 & $0.522(0.204-1.287)$ \\
Radiotherapy & 0.0917 & $0.437(0.167-1.144)$ \\
\hline
\end{tabular}

*Statistically significant difference $(p<0.05)$ from preoperative Karnofsky performance status (KPS) score $(<70)$.

predictors of longer survival duration. However, multivariate analyses showed preoperative KPS score $(\geq 70)$ was the only independent predictor of survival (Table 2). Median survival was 14.5 months in patients with preoperative KPS score $\geq 70$, compared to 5 months for those with preoperative KPS score $<70$.

\section{Discussion}

The present study analyzed the prognostic factors of elderly patients with supratentorial malignant gliomas. Univariate analysis demonstrated that the preoperative KPS score $\geq 70$ and radiation therapy were significant prognostic factors, whereas multivariate analyses showed radiation therapy lost its statistical significance due to selection bias, so the preoperative KPS score $\geq 70$ was the only independent prognostic factor. According to our results, only patients with good preoperative KPS score may benefit from aggressive treatment, including extensive resection and full-dose irradiation. Similarly, aggressive surgery and radiation therapy extended survival in elderly patients with good performance status. $^{30,31,34,42,45)}$ However, few reports have considered the importance of combination treatment with surgery, radiation therapy, and chemotherapy, regardless of the pretreatment KPS score. ${ }^{33)}$

Previous reports of improved survival benefit for patients receiving radical resection of malignant astrocytomas have been criticized for selection bias. Patients receiving partial resection or biopsy were often older, had a lower performance status, and so had a lower chance of receiving adjuvant therapies. A recent small randomized trial included 23 patients aged greater than 65 years with malignant glioma assigned to only biopsy or resection with radiation therapy. ${ }^{43)}$ The median survival time was significantly longer in patients who underwent resection (5.6 months) than in those who underwent biopsy $(2.8$ months). In general, surgical treatment for elderly patients carries the risk of high mortality and morbidity. Overall morbidity, including neurological and general complications, occurs in $30 \%$ to $50 \%$ of the elderly subpopulation..$^{7,15,21,41)}$ Medical complication rates seem to become higher with increasing age compared with neurological morbidity. $\left.{ }^{6}\right)$ Our overall complication total was 14 of 30 , with more medical complications than neurological complications. The decision to carry out radical surgery on elderly patients with malignant gliomas should be based on careful consideration of the patient's condition, including performance, mental and neurological status, and tumor location. Geriatric medicine often considers 65 years and older as elderly, although the definition varies. ${ }^{4}$ We used an age limit of 70 years, because 65 years and younger are no longer considered as elderly. In our series, the oldest patient who underwent surgery was an 81-yearold woman. However, we now consider that radical treatment should be indicated only for patients aged 80 years or younger.

Our single-institution retrospective study was based on a relatively small number of patients. Histological grade was not an independent prognostic factor, which is consistent with the recent largest series of the Glioma Outcome Project, which showed very little difference in survival time between patients with grade 3 and grade 4 malignant gliomas. ${ }^{25)} \mathrm{A}$ diagnosis of grade 3 tumor might be a result of tissue sampling error of glioblastoma, or grade 3 tumor in the elderly may behave just as aggressively as glioblastoma, with indistinguishable biological properties.

There is now considerable concern over the optimal adjuvant therapies for elderly patients with malignant gliomas. Although the elderly appear to be susceptible to radiation-induced brain injury, radiation therapy remains the gold standard even for elderly patients with malignant gliomas. ${ }^{3,17)}$ Radiotherapy was the only prognostic factor for survival in this subgroup, and radiotherapy was recommended for all elderly patients. ${ }^{28)}$ Other studies have also shown a survival advantage for radiotherapy, although the benefit is observed only in patients aged 70 years or younger, and patients with good performance status or resection. ${ }^{1,34,42)}$ The survival benefit of radiotherapy was minimal, but improvement in symptoms was found.1,29) Short-course radiotherapy is also recommended for the elderly. ${ }^{1-3,37,42)}$ A prospective randomized trial found no difference in survival between patients receiving standard radiation therapy (60 Gy in 30 fractions over 6 weeks) or short-course radiation therapy ( 40 Gy in 15 fractions over 3 weeks). ${ }^{37)}$ In our series, we 
used a stereotactic radiosurgery boost for recurrence in six patients, who were likely to have good performance status or longer survival period. Stereotactic radiosurgery boost appears useful for treatment of recurrent malignant gliomas, ${ }^{2,19)}$ but the effectiveness in the elderly subpopulation should be clarified.

Chemotherapy as the only adjuvant therapy has not been advocated for the elderly because malignant gliomas are chemoresistant and nitrosoureabased chemotherapies are associated with significant myelosuppression. ${ }^{4}$ Recently, temozolomide has been introduced to the clinical setting. A randomized multicenter trial demonstrated an increase in 2-year survival from $10 \%$ to $26 \%$ in glioblastoma patients aged 71 years and younger with the addition of temozolomide to radiotherapy. ${ }^{40)}$ The effectiveness and safety of temozolomide treatment have been demonstrated in the elderly. ${ }^{5,8}$ Temozolomide single-agent therapy improves neurological status and is as effective as irradiation in increasing survival in elderly glioblastoma patients with or without resection.8, ${ }^{8,16)}$ Therefore, temozolomide would be now considered a viable alternative to radiation therapy, especially in elderly patients. ${ }^{4,5,8,16)}$ Prospective randomized studies are now investigating the optimum therapeutic options for efficacy, toxicity, convenience, and quality of life for the elderly. ${ }^{4}$ )

The present study indicates that performance status rather than histological grade is the key prognostic factor in elderly patients with supratentorial malignant gliomas. Elderly patients with a good preoperative KPS can be treated aggressively with extensive resection and radiotherapy. Elderly patients with poor performance status should not undergo surgery or radiation, but administration of temozolomide should be considered.

\section{References}

1) Bauman GS, Gaspar LE, Fisher BJ, Halperin EC, Macdonald DR, Cairncross JG: A prospective study of short-course radiotherapy in poor prognosis glioblastoma multiforme. Int J Radiat Oncol Biol Phys 29: 835-839, 1994

2) Baumert BG, Lutterbach J, Bernays R, Davis JB, Heppner FL: Fractionated stereotactic radiotherapy boost after post-operative radiotherapy in patients with high-grade gliomas. Radiother Oncol 67: 183-190, 2003

3) Brada M, Stenning SP: Radiotherapy for malignant gliomas in the elderly. Semin Oncol 30 (6 Suppl 19): 63-67, 2003

4) Brandes AA, Compostella A, Blatt V, Tosoni A: Glioblastoma in the elderly: current and future trends. Crit Rev Oncol Hematol 60: 256-266, 2006

5) Brandes AA, Vastola F, Basso U, Berti F, Pinna G, Rotilio A, Gardiman M, Scienza R, Monfardini S, Ermani M: A prospective study on glioblastoma in the elderly. Cancer 97: 657-662, 2003

6) Brell M, Ibanez J, Caral L, Ferrer E: Factors influencing surgical complications of intra-axial brain tumours. Acta Neurochir (Wien) 142: 739-750, 2000

7) Cabantog AM, Bernstein M: Complications of first craniotomy for intra-axial brain tumour. Can J Neurol Sci 21: 213-218, 1994

8) Chinot OL, Barrie M, Frauger E, Dufour H, FigarellaBranger D, Palmari J, Braguer D, Hoang-Xuan K, Moktari K, Peragut JC, Martin PM, Grisoli F: Phase II study of temozolomide without radiotherapy in newly diagnosed glioblastoma multiforme in an elderly populations. Cancer 100: 2208-2214, 2004

9) Committee of Brain Tumor Registry of Japan: Report of Brain Tumor Registry of Japan (1969-1996). Neurol Med Chir (Tokyo) 43 Suppl: 1-111, 2003

10) Curran WJ Jr, Scott CB, Horton J, Nelson JS, Weinstein AS, Fischbach AJ, Chang CH, Rotman M, Asbell SO, Krisch RE, Nelson DF: Recursive partitioning analysis of prognostic factors in three Radiation Therapy Oncology Group malignant glioma trials. J Natl Cancer Inst 85: 704-710, 1993

11) Davis DL, Hoel D, Fox J, Lopez A: International trends in cancer mortality in France, West Germany, Italy, Japan, England and Wales, and the USA. Lancet 336: 474-481, 1990

12) Deorah S, Lynch CF, Sibenaller ZA, Ryken TC: Trends in brain cancer incidence and survival in the United States: Surveillance, Epidemiology, and End Results Program, 1973 to 2001. Neurosurg Focus 20(4): E1, 2006

13) Devaux BC, O’Fallon JR, Kelly PJ: Resection, biopsy, and survival in malignant glial neoplasms: A retrospective study of clinical parameters, therapy, and outcome. J Neurosurg 78: 767-775, 1993

14) Fleury A, Menegoz F, Grosclaude P, Daures JP, Henry-Amar M, Raverdy N, Schaffer P, Poisson M, Delattre JY: Descriptive epidemiology of cerebral gliomas in France. Cancer 79: 1195-1202, 1997

15) Fujimura $M$, Kumabe $T$, Tominaga $T$, Jokura $H$, Shirane R, Yoshimoto T: Routine clinical adoption of magnetic resonance imaging was associated with better outcome after surgery in elderly patients with a malignant astrocytic tumour: a retrospective review. Acta Neurochir (Wien) 146: 251-255, 2004

16) Glantz M, Chamberlain M, Liu Q, Litofsky NS, Recht LD: Temozolomide as an alternative to irradiation for elderly patients with newly diagnosed malignant gliomas. Cancer 97: 2262-2266, 2003

17) Grau JJ, Verger E, Brandes AA, Rigon A, Monfardini S, DeAngelis LM: Radiotherapy of the brain in elderly patients. Eur J Cancer 36: 443-452, 2000

18) Greig NH, Ries LG, Yancik R, Rapoport SI: Increasing annual incidence of primary malignant brain tumors in the elderly. J Natl Cancer Inst 82: 
1621-1624, 1990

19) Hsieh PC, Chandler JP, Bhangoo S, Panagiotopoulos K, Kalapurakal JA, Marymont MH, Cozzens JW, Levy RM, Salehi S: Adjuvant gamma knife stereotactic radiosurgery at the time of tumor progression potentially improves survival for patients with glioblastoma multiforme. Neurosurgery 57: 684-692, 2005

20) Keles GE, Anderson B, Berger MS: The effect of extent of resection on time to tumor progression and survival in patients with glioblastoma multiforme of the cerebral hemisphere. Surg Neurol 52: 371-379, 1999

21) Kelly PJ, Hunt C: The limited value of cytoreductive surgery in elderly patients with malignant gliomas. Neurosurgery 34: 62-67, 1994

22) Kowalczuk A, Macdonald RL, Amidei C, Dohrmann G 3rd, Erickson RK, Hekmatpanah J, Krauss S, Krishnasamy S, Masters G, Mullan SF, Mundt AJ, Sweeney P, Vokes EE, Weir BK, Wollman RL: Quantitative imaging study of extent of surgical resection and prognosis of malignant astrocytomas. Neurosurgery 41: 1028-1038, 1997

23) Kreth FW, Berlis A, Spiropoulou V, Faist M, Scheremet R, Rossner R, Volk B, Ostertag CB: The role of tumor resection in the treatment of glioblastoma multiforme in adults. Cancer 86: 2117-2123, 1999

24) Lacroix M, Abi-Said D, Fourney DR, Gokaslan ZL, Shi W, DeMonte F, Lang FF, McCutcheon IE, Hassenbusch SJ, Holland E, Hess K, Michael C, Miller D, Sawaya R: A multivariate analysis of 416 patients with glioblastoma multiforme: Prognosis, extent of resection, and survival. J Neurosurg 95: 190-198, 2001

25) Laws ER, Parney IF, Huang W, Anderson F, Morris AM, Asher A, Lillehei KO, Bernstein M, Brem $\mathrm{H}$, Sloan A, Berger MS, Chang S; Glioma Outcomes Investigators: Survival following surgery and prognostic factors for recently diagnosed malignant glioma: data from the Glioma Outcomes Project. J Neurosurg 99: 467-473, 2003

26) Lowry JK, Snyder JJ, Lowry PW: Brain tumors in the elderly: recent trends in a Minnesota cohort study. Arch Neurol 55: 922-928, 1998

27) Mangiola A, Maira G, De Bonis P, Porso M, Pettorini B, Sabatino G, Anile C: Glioblastoma multiforme in the elderly: A therapeutic challenge. J Neurooncol 76: 159-163, 2006

28) Marijnen CA, van den Berg SM, van Duinen SG, Voormolen JH, Noordijk EM: Radiotherapy is effective in patients with glioblastoma multiforme with a limited prognosis and in patients above 70 years of age: a retrospective single institution analysis. Radiother Oncol 75: 210-216, 2005

29) Meckling S, Dold O, Forsyth PA, Brasher P, Hagen NA: Malignant supratentorial glioma in the elderly: is radiotherapy useful? Neurology 47: 901-905, 1996

30) Mohan DS, Suh JH, Phan JL, Kupelian PA, Cohen $\mathrm{BH}$, Barnett GH: Outcome in elderly patients undergoing definitive surgery and radiation therapy for supratentorial glioblastoma multiforme at a tertiary care institution. Int J Radiat Oncol Biol Phys 42: 981-987, 1998

31) Muacevic A, Kreth FW: Quality-adjusted survival after tumor resection and/or radiation therapy for elderly patients with glioblastoma multiforme. J Neurol 250: 561-568, 2003

32) Nazzaro JM, Neuwelt EA: The role of surgery in the management of supratentorial intermediate and high-grade astrocytomas in adults. J Neurosurg 73: 331-344, 1990

33) Patwardhan RV, Shorter C, Willis BK, Reddy P, Smith D, Caldito GC, Nanda A: Survival trends in elderly patients with glioblastoma multiforme: resective surgery, radiation, and chemotherapy. Surg Neurol 62: 207-215, 2004

34) Pierga JY, Hoang-Xuan K, Feuvret L, Simon JM, Cornu P, Baillet F, Mazeron JJ, Delattre JY: Treatment of malignant gliomas in the elderly. J Neurooncol 43: 187-193, 1999

35) Quigley MR, Maroon JC: The relationship between survival and the extent of the resection in patients with supratentorial malignant gliomas. Neurosurgery 29: 385-389, 1991

36) Radhakrishnan K, Mokri B, Parisi JE, O’Fallon WM, Sunku J, Kurland LT: The trends in incidence of primary brain tumors in the population of Rochester, Minnesota. Ann Neurol 37: 67-73, 1995

37) Roa W, Brasher PM, Bauman G, Anthes M, Bruera E, Chan A, Fisher B, Fulton D, Gulavita S, Hao C, Husain S, Murtha A, Petruk K, Stewart D, Tai P, Urtasun R, Cairncross JG, Forsyth P: Abbreviated course of radiation therapy in older patients with glioblastoma multiforme: a prospective randomized clinical trial. J Clin Oncol 22: 1583-1588, 2004

38) Salminen E, Nuutinen JM, Huhtala S: Multivariate analysis of prognostic factors in 106 patients with malignant glioma. Eur J Cancer 32A: 1918-1923, 1996

39) Stark AM, Hedderich J, Held-Feindt J, Mehdorn HM: Glioblastoma - the consequences of advanced patient age on treatment and survival. Neurosurg Rev 30: 56-62, 2007

40) Stupp R, Mason WP, van den Bent MJ, Weller M, Fisher B, Taphoorn MJ, Belanger K, Brandes AA, Marosi C, Bogdahn U, Curschmann J, Janzer RC, Ludwin SK, Gorlia T, Allgeier A, Lacombe D, Cairncross JG, Eisenhauer E, Mirimanoff RO; European Organisation for Research and Treatment of Cancer Brain Tumor and Radiotherapy Groups; National Cancer Institute of Canada Clinical Trials Group: Radiotherapy plus concomitant and adjuvant temozolomide for glioblastoma. N Engl J Med 352: 987-996, 2005

41) Tomita T, Raimondi AJ: Brain tumors in the elderly. JAMA 246: 53-55, 1981

42) Villa S, Vinolas N, Verger E, Yaya R, Martinez A, Gil M, Moreno V, Caral L, Graus F: Efficacy of radiotherapy for malignant gliomas in elderly patients. Int J Radiat Oncol Biol Phys 42: 977-980, 1998 
43) Vuorinen V, Hinkka S, Farkkila M, Jaaskelainen J: Debulking or biopsy of malignant glioma in elderly people: A randomised study. Acta Neurochir (Wien) 145: 5-10, 2003

44) Werner MH, Phuphanich S, Lyman GH: The increasing incidence of malignant gliomas and primary central nervous system lymphoma in the elderly. Cancer 76: 1634-1642, 1995

45) Whittle IR, Basu N, Grant R, Walker M, Gregor A: Management of patients aged $>60$ years with malignant glioma: good clinical status and radiotherapy determine outcome. Br J Neurosurg 16: 343-347, 2002

Address reprint requests to: Masanori Kurimoto, M.D., Department of Neurosurgery, University of Toyama, 2630 Sugitani, Toyama 930-0194, Japan.

e-mail: kuri3312@med.u-toyama.ac.jp

\section{Commentary}

The authors retrospectively analyzed 30 patients aged 70 years old or over with supratentorial malignant gliomas treated by surgery. They found that KPS score of 70 or greater and radiation therapy were significantly associated with longer survival with univariate analysis and that KPS score of 70 or greater was the only independent prognostic factor with multivariate analysis. So, the authors suggested that patients with good preoperative KPS score should be aggressively treated with resection and radiotherapy. This is a nice statistical research with detailed analysis. But clinically the prognostic factor is complex. I think the only limitation of this study is the sample size. If more cases were added into this study, other positive prognostic factors would be found. We expect a further larger sample size study.

Shengde BAO, M.D. Department of Neurosurgery Peking University First Hospital Beijing, P.R.C.

This paper notes the apparent increased incidence in industrialized countries of malignant gliomas in elderly patients, which may represent either a true increased incidence, or may simply indicate increased access to diagnostic scans in this population. It also draws attention to the fact that, in many countries, elderly patients may be considered unsuitable for surgical resection or for adjuvant treatment solely on the grounds of age because it is assumed they have a uniformly poor prognosis as well as poor tolerance of invasive therapies. The authors describe in this series of 30 patients the results of what is intensive treatment and which is, at least judged by European practice, unusually radical treatment. Their conclusion is that performance status, rather than histological grade, should indicate whether the individual patient should be treated by extensive resection and radiotherapy. In selected patients there can be relatively good results. They conclude that such treatment is not suitable for those with poor performance status.

David G. T. Thомаs, M.A., F.R.C.P., F.R.C.S. Institute of Neurology The National Hospital for Neurology and Neurosurgery London, U.K. 